\title{
Incidence and Relative Prevalence of Distinct Caulimoviruses (Genus Caulimovirus, Family Caulimoviridae) Associated with Dahlia Mosaic in Dahlia variabilis
}

V. Pahalawatta, Department of Plant Pathology, Washington State University, P.O. Box 99164-6430, Pullman, 99164; R. Miglino, Dutch Flower Bulb Inspection Service, P.O. Box 300, 2160 AH Lisse, the Netherlands; K. B. Druffel, Department of Plant Pathology, Washington State University, P.O. Box 99164-6430, Pullman, 99164; A. Jodlowska and A. R. van Schadewijk, Dutch Flower Bulb Inspection Service, P.O. Box 300, 2160 AH Lisse, the Netherlands; and H. R. Pappu, Department of Plant Pathology, Washington State University, P.O. Box 99164-6430, Pullman, 99164

\begin{abstract}
Pahalawatta, V., Miglino, R., Druffel, K. B., Jodlowska, A., van Schadewijk, A. R., and Pappu, H. R. 2007. Incidence and relative prevalence of distinct caulimoviruses (genus Caulimovirus, family Caulimoviridae) associated with dahlia mosaic in Dahlia variabilis. Plant Dis. 91:1194-1197.

Dahlia mosaic, caused by Dahlia mosaic virus (DMV), is one of the most important viral diseases of dahlia. Molecular characterization of DMV showed the association of two distinct caulimoviruses (DMV-D10, DMV-Portland) and a D10-like sequence variant (DMV-Holland) with the disease. Using primers specific to these two viruses and the sequence variant, a polymerase chain reaction-based assay was used to determine their relative incidence in several dahlia samples from the United States and the Netherlands. Testing was done on samples collected in 2005 and 2006 in the United States and in 2006 in the Netherlands. Results indicated the predominance of DMV-D10 over DMV-Portland and DMV-Holland in both the United States and the Netherlands. Using conserved regions of the viral genome, primers were designed and used to detect all three sequences. Results suggested that DMV-D10 is predominantly associated with dahlia mosaic, but diagnostics should also include testing for DMV-Portland and DMV-Holland.
\end{abstract}

Dahlia mosaic virus (DMV) of genus Caulimovirus and family Caulimoviridae is one of the most important viruses of dahlia (Dahlia variabilis) in the United States (6) and several other parts of the world $(1,3)$. Symptoms caused by DMV include mosaic, chlorotic vein banding, and leaf malformation (7). DMV is geographically widespread, but the natural host range is limited to Dahlia spp. A survey by Pappu et al. (8) of dahlias collected from several states in the United States, using a polymerase chain reaction (PCR)based detection assay, showed a very high incidence of DMV in dahlias. Accurate and reliable detection of the virus is required for developing effective virus elimination programs. Based on the partial molecular characterization of the DMV genome, PCR-based detection of DMV was reported $(2,4,8)$.

As part of an ongoing study to determine the sequence variability of the DMV genome, we identified a distinct caulimovirus in dahlia, referred to as DMV-D10 (5), which was found to be distinct from another caulimovirus (DMV-Portland)

Corresponding author: H. R. Pappu
E-mail: hrp@wsu.edu

Accepted for publication 26 April 2007.

doi:10.1094/PDIS-91-9-1194

(c) 2007 The American Phytopathological Society
(11). Partial genomic sequence representing the viral coat protein and reverse transcriptase genes of another isolate, referred to as DMV-Holland, has been reported (4). While our previous survey for the incidence of DMV-D10 showed its widespread occurrence in the United States (8), no information is available on the incidence of DMV-Portland. Moreover, no information is available on the incidence of DMV-Holland in Europe or in the United States. Due to the continuous movement of dahlia planting material within the United States and between the United States and Europe, the relative incidence of these viruses should be ascertained in order to devise effective and comprehensive detection and virus elimination strategies. In this study, using primers specific to DMV-D10, DMV-Portland, and DMV-Holland, the relative incidence was determined in samples collected from several states in the United States and from the Netherlands.

Table 1. Primers used for the detection of Dahlia mosaic virus (DMV)-D10, DMV-Portland, and DMV-Holland in Dahlia pinnata

\begin{tabular}{|c|c|c|c|c|}
\hline $\begin{array}{l}\text { GenBank } \\
\text { accession }\end{array}$ & Primer pair & Sequence $\left(5^{\prime}-3^{\prime}\right)$ & $\begin{array}{l}\mathbf{T}_{\mathbf{m}} \\
\left({ }^{\circ} \mathbf{C}\right)\end{array}$ & $\begin{array}{l}\text { Expected } \\
\text { size (bp) }\end{array}$ \\
\hline & $\begin{array}{l}\text { DMV-D10 } \\
\text { ORF1-START } \\
\text { ORF1-END1 }\end{array}$ & $\begin{array}{l}\text { ATGGATCGTAAAGATT } \\
\text { CTGTTTTTCTGTGTTTCTACTGG }\end{array}$ & 50 & 900 \\
\hline & $\begin{array}{l}\text { ORF4CP1-1431Fa } \\
\text { ORF4CPI-1926C }\end{array}$ & $\begin{array}{l}\text { TGCATAAAATGAGTTCTATC } \\
\text { TGAACTTGTTCATCATTATC }\end{array}$ & 58 & 480 \\
\hline & $\begin{array}{l}\text { ORF6-START } \\
\text { ORF6-END1 }\end{array}$ & $\begin{array}{l}\text { ATGGAAGAAATTAAGGCGT } \\
\text { TTGTCTTCATCCATAAAGCAG }\end{array}$ & 60 & 1,280 \\
\hline AY291585 & $\begin{array}{l}\text { DMV-Portland } \\
\text { KORF1-F } \\
\text { KORF1-R }\end{array}$ & $\begin{array}{l}\text { ATG AAT ATC TTA GAA AGG AA } \\
\text { CTT AAT CCT TAA GTT ATC AA }\end{array}$ & 50 & 966 \\
\hline AY291586 & $\begin{array}{l}\text { Kapht-F } \\
\text { Kapht-R }\end{array}$ & $\begin{array}{l}\text { ATG AGT AAT GCT TCA GCA A } \\
\text { TGA CCA TGG CTT CTA ACT GT }\end{array}$ & 56 & 504 \\
\hline AY291587 & $\begin{array}{l}\text { KDNAb-F } \\
\text { KDNAb-R }\end{array}$ & $\begin{array}{l}\text { TGA CCA CCA TCA AAG ACT TA } \\
\text { TCA TAC TGG AGG CCA TTT TA }\end{array}$ & 59 & 363 \\
\hline AY291588 & $\begin{array}{l}\text { Kcp-F } \\
\text { Kcp-R }\end{array}$ & $\begin{array}{l}\text { ATG GCC TCC AGT ATG AAA G } \\
\text { TTA TTC TGT TCC TGA TGA TT }\end{array}$ & 53 & 1,476 \\
\hline AY309479 & $\begin{array}{l}\text { Kpoly-F } \\
\text { Kpoly-R }\end{array}$ & $\begin{array}{l}\text { ATG TTG TCA CAA CAG ATG AT } \\
\text { ATT CTT TTT CAT TAC TAT GG }\end{array}$ & 50 & 1,830 \\
\hline AY309480 & $\begin{array}{l}\text { KIB-F } \\
\text { KIB-R }\end{array}$ & $\begin{array}{l}\text { ATG GAG GAA GAA TTA AAA GC } \\
\text { TTA TAT AGG CAA GTC TTC AG }\end{array}$ & 51 & 1,515 \\
\hline AJ515906 & $\begin{array}{l}\text { DMV-Holland } \\
\text { DenORF4-F } \\
\text { DenORF4-R1 }\end{array}$ & $\begin{array}{l}\text { TCCAAGCAGACAGACAAACC } \\
\text { ATTGCATTTCATTTAGAACA }\end{array}$ & 56 & 600 \\
\hline AJ515906 & $\begin{array}{l}\text { DenORF4-F1 } \\
\text { DenORF4-R }\end{array}$ & $\begin{array}{l}\text { CAGCAAGAAACAGGAATTGA } \\
\text { TTTAGCAGCTTCGACTGTAAA }\end{array}$ & 60 & 600 \\
\hline
\end{tabular}

${ }^{a}$ Reference (8). 


\section{MATERIALS AND METHODS}

Source of dahlia samples. One hundred and nineteen dahlia plant samples collected from commercial nurseries in California, Georgia, Montana, New Mexico, and Oklahoma, and from dahlia varietal trial gardens in Maryland and Washington State during 2005 and 2006 were used in the study. In addition, 41 samples from field-grown dahlia plants from a dahlia varietal trial garden in Lisse, the Netherlands collected in 2006 were used. Samples were collected at random irrespective of the presence of symptoms suggestive of virus infection.
Total nucleic acid purification. Total nucleic acid was purified according to a modified Dellaporta procedure (9). Approximately $0.1 \mathrm{~g}$ (or a quarter-sized leaf piece) was used for DNA extraction.

Primers used in PCR. Several primer pairs encompassing different regions of the viral genomes were designed for the specific detection of the caulimoviruses associated with the disease. One set consisting of three primer pairs, designated DMV-D10, was designed for the specific detection of DMV-D10 (Table 1). A second set, designated DMV-Portland (11) and consisting of six primer pairs, and a third set, designated
DMV-Holland (4), were designed based on the sequences available in GenBank, for the specific detection of DMV-Portland and DMV-Holland, respectively (Table 1). Two DMV-D10, three DMV-Portland, and two DMV-Holland primer pairs were used for exclusive detection of the two viruses and the sequence variant, respectively, in the dahlia samples. A primer pair, Den518F/Den1156C, that could detect DMV-D10, -Holland, and -Portland was designed based on the conserved region of the 1,171-bp sequence representing partial open reading frames of coat protein and the reverse transcriptase genes (Fig. 1).

$$
\begin{aligned}
& \text { D10 } \\
& \text { Portland } \\
& \text { Holland } \\
& \text { D10 } \\
& \text { Portland } \\
& \text { Holland } \\
& \text { D10 } \\
& \text { Portland } \\
& \text { Holland } \\
& \text { D10 } \\
& \text { Portland } \\
& \text { Holland } \\
& \text { D10 } \\
& \text { Portland } \\
& \text { Holland } \\
& \text { D10 } \\
& \text { Portland } \\
& \text { Holland } \\
& \text { D10 } \\
& \text { Portland } \\
& \text { Holland } \\
& \text { D10 } \\
& \text { Portland } \\
& \text { Holland } \\
& \text { D10 } \\
& \text { Portland } \\
& \text { Holland } \\
& \text { D10 } \\
& \text { Portland } \\
& \text { Holland } \\
& \text { D10 } \\
& \text { Portland } \\
& \text { Holland }
\end{aligned}
$$

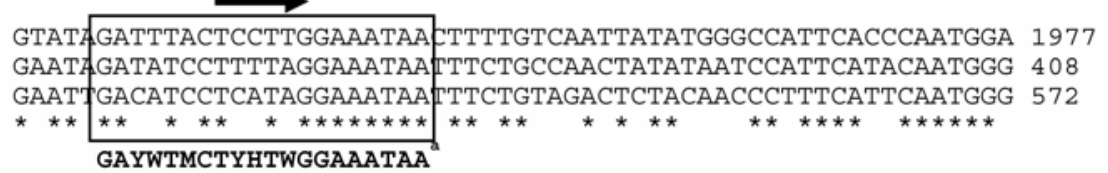

TTGACAGAATATCTTTTCATCTTAATCAAGAAAT------GATTTTGATCAAAAAGATAA 2031 TTGACCGGATTGCTTTTCACAAAAATGAAGAGAT------AATTCTTGTACCTAAAGTAC 462 AAGATAGAATTGCATTTCATTTAGAACAAGGAACCAAACAAATCCTAGTTCCTAAACAAA 632

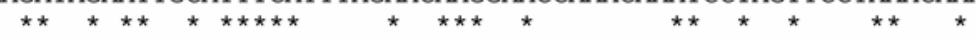

CAAAAGCTTTTCAAATTGGAAAAACTGGTTTCTTGAATCCATGAAAAAAGATTCAAAAA 2091 GAAAAGCCATGAGAAAAGGATATGAAGGTTTCCTTAAAACCATGGAAAGAGATTCAAAAT 522 GAAAAGCAATAAAAAGAGGTTATCAAGGATTCCTTGAAACCATGAAGAAAGAGTCAAACA 692

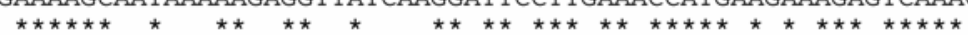

CTAAACAAATTCCGGGTACCAATATAACCCAAGAAGTTATAAAACCGGAAA--GATTTTT 2149 CTCAGCCTACCCCAGGCACCAACATTACCCAAGAGGTAATTGATGAAGAAAACAACTTCA 582 CTCAACCACTGCCAGGTACGAACATCACCAAAGAAGCAGTAGAAGATGAAAGCAACTTCA 752

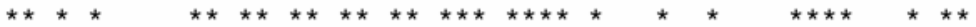

TC-TTGAAATACAGAGATATCAAAAAATTGAAGATCTACTTGAAAAAGTATGTTTTGAAA 2208 TCATTGATATCTCCAGATATCAAGAGATTCAAGAACTACTTAAGAGAGTATGTTCAGAAA 642 TCATAGATATCTCAAGATATCAAGAGATTCAAAACTTACTTGAAAAAGTTTGTTCTGAAA 812

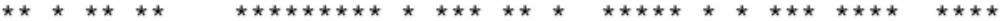

ACCCTATTGACCCAGAAAAGTCCAAATACTGGATGAATGCCTCAATAGAATTAATAGATC 2268 ATCCTATTGATCCTCAGAAGTCTAAAGGATGGATGACGGCATCAATAAAACTTGCTGACC 702 ATCCTTTAGACCCAGCCAAATCCAAAGCGTGGATGAAAGCATCAATAAAACTAGCTGATC 872

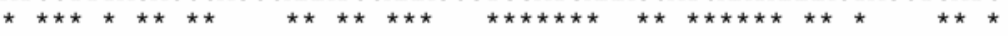
CCAAAACCGTGGTTAGGGTAAAACCCATGAAATATAGTCCACAGGATCGCGAAGAATTTG 2328 CAAAGTCAGTAGTTAAGGTGAAACCAATGGTTTATTCACCACAGGATAGAAAGGAATTCG 762 CAAAATCAGTAGTCAGAGTCAAACCTATGGTTTACTCACCAGAAGACAGAAAAGAGTYTG 932

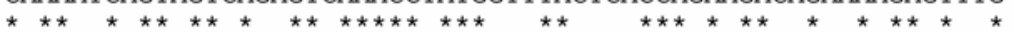

GTAAGCAAATCAAAGAATTACTTGATTTAAAATTAATTATTCCAAGTAAATCTCCTCACA 2388 AAATCCAAATTAAGGAACTCCTTAATCTTAAGGTAATAATTCCAAGTAAATCCCAACACA 822 AGATTCAAATTAAGGAACTCCTTGACCTAAAAGTCATAGAACCCAGCRAATCTCAACACA 992

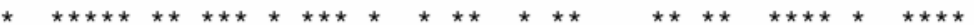

TGTCTCCAGCTTTTCTTGTAGAAAACGAAGCAGAAAAAAGGAGAGGAAAAAAGCGCAGGG 2448 TGTCCCCTGCTTTTCTCGTTGAAAAAGAAGCAGAAAAACGACGTGGCAAGAAAAGAATGG 882 TGYCACCCGCCTTTTTGGTTGAAAAGGAGCGGAAAAAGAAGAGGAAAAAAGAGAATGG 1052

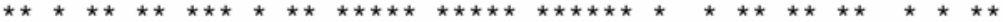

TTGTAAATTATAAGGCAATTAATGCAGCTACCAAAGGAGACAGCCATAATCTTCCTTGTA 2508 TTGTTAACTATAAAAAGTTAAATGAAGTCACCATTGGTGATTCTCACAACCTTCCTAACA 942 TCGTTAACTACAAAAAGTTAAACGAAGTCACCATTGGTGATTCTCACAACCTTCCCAACA 1112

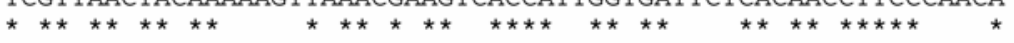

TGCAGGAATTATTAACCCTCTTAAGAGGAAAAACCATTTTTTCTACTTTCGACTGCAAGA 2568 TGCAAGAGTTAATTACTCTTCTTAGAGGAAAATCTATCTTTAGCAGTTTTGACTGTAAAA 1002 TGCAAGAGTTAATCACTCTGCTCAGAGGAAAAACCATCTTTAGCAGCTTCGACTGTAAA- 1171

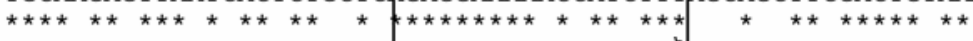
CTCCTTTTWGRTARAAA

Fig. 1. Nucleotide sequence alignment of the reverse transcriptase gene of Dahlia mosaic virus (DMV)-D10 (unpublished), DMV-Portland (GenBank accession AY309479), and DMV-Holland (GenBank accession AJ515906) using CLUSTAL W (12). * $=$ identical nucleotides. Boxed regions denote the sequence used to design degenerate primer Den518- $\mathrm{F}^{\mathrm{a}}$ and Den $1156 \mathrm{C}^{\mathrm{b}}$. Degenerate primer sequences are given in bold. 
PCR amplification. Two microliters of 1:5 diluted total nucleic acid from above was used in each PCR reaction containing $2 \mu \mathrm{l} 10 \times$ PCR buffer (Invitrogen, Carlsbad, CA), $1.2 \mu \mathrm{l} 2.5 \mathrm{mM}$ dNTPs, $0.8 \mu \mathrm{l} 50 \mathrm{mM}$ $\mathrm{MgCl}_{2}, 0.6 \mu \mathrm{l} 20 \mu \mathrm{M}$ primer $1,0.6 \mu \mathrm{l} 20$ $\mu \mathrm{M}$ primer 2, $13.6 \mu \mathrm{l} \mathrm{ddH}_{2} \mathrm{O}$, and $0.2 \mu \mathrm{l}$ Taq DNA polymerase (Invitrogen). PCR amplification was performed in a DNA thermal cycler (BioRad, Hercules, CA) programmed for $3 \mathrm{~min}$ at $94^{\circ} \mathrm{C}$ for initial denaturation and 50 cycles each consisting of a denaturation step at $94^{\circ} \mathrm{C}$ for $30 \mathrm{~s}$, the required annealing temperature based on the primer pair used at $20 \mathrm{~s}$, and an extension step at $72^{\circ} \mathrm{C}$ determined based on the size of the amplicon to be synthesized at the rate of $1,000 \mathrm{bp}$ of PCR per minute followed by a final extension for $7 \mathrm{~min}$ at $72^{\circ} \mathrm{C}$. PCR reactions $(7.5 \mu \mathrm{l})$ were analyzed by agarose gel electrophoresis.

Cloning and sequencing. PCR products of expected size were cloned using pGEMT (Promega, Madison, WI) or TOPO TA (Invitrogen) cloning kits. Some PCR products were sequenced directly after purification using QIAquick PCR purification kit (Qiagen, Valencia, CA). Nucleotide sequences were determined using the $\mathrm{ABI}$ Prism sequencing system at the Molecular Biology Core Laboratory of Washington State University, Pullman. Recombinant plasmids were sequenced using M13 forward and reverse primers, and PCR products were sequenced using the specific primer pairs that were initially used to obtain the PCR product.

Sequence analysis. Sequences were compiled using PC-based AlignX (Vector
NTI Suite 9, Informax Inc., Bethesda, MD) or SeqAid (10) software. Multiple alignments were generated using CLUSTAL W (12). Sequences of DMV available in GenBank were used for comparisons. Primers were designed by using Primer Designer version 2.0 (Scientific and Educational Software, Cary, NC).

\section{RESULTS AND DISCUSSION}

Each of the primer pairs used produced a specific amplicon of expected size. Amplicons resulting from using each of the primer pairs were sequenced to verify their identity. A majority of the dahlia leaf samples collected in the United States $(87.4 \%)$ and the Netherlands (97.6\%) produced amplicons of expected size with the DMVD10 primers. Results of PCR using the DMV-Portland specific primers showed fewer positives, with $21.8 \%$ of the U.S. samples and $53.6 \%$ of the samples from the Netherlands producing amplicons of expected size. In contrast, $97.6 \%$ of the samples from the Netherlands produced amplicons of expected size with DMVHolland primers, whereas only $31.9 \%$ of the U.S. samples tested positive (Table 2). Only $6.7 \%$ of the samples from the United States tested positive for all three viruses, whereas $36.6 \%$ of samples tested from the Netherlands were positive for all three. All samples positive with DMV-Portland were also positive for either DMV-D10 or DMV-Holland. The percentage of U.S. samples positive for both DMV-D10 and DMV-Holland was $28.6 \%$, whereas $21.0 \%$ of the samples were positive for both DMV-D10 and DMV-Portland. A similar

Table 2. Percentage of dahlia samples positive for caulimoviruses associated with dahlia

\begin{tabular}{lcc}
\hline Primer set & United States & Netherlands \\
\hline DMV-D10 & 87.4 & 97.6 \\
DMV-Portland & 21.8 & 53.6 \\
DMV-Holland & 31.9 & 97.6 \\
DMV-D10 + DMV-Portland & 21.0 & 43.9 \\
DMV-D10 + DMV-Holland & 28.6 & 97.6 \\
DMV-Portland + DMV-Holland & 6.7 & 17.1 \\
DMV-D10 + DMV-Portland + DMV-Holland & 6.7 & 36.6 \\
Negative & 4.2 & 0 \\
\hline
\end{tabular}

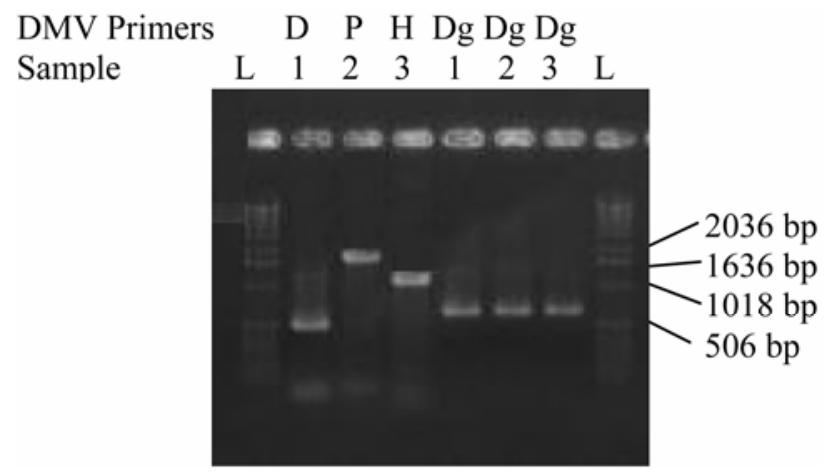

Fig. 2. Agarose gel electrophoresis of polymerase chain reaction (PCR) products from DNA extracts of three dahlia samples amplified with primers specific to Dahlia mosaic virus (DMV)-D10 (D), DMV-Portland (P), DMV-Holland $(\mathrm{H})$, and degenerate $(\mathrm{Dg})$ primers that could amplify all three caulimoviruses associated with dahlia. $\mathrm{L}=1$-kb ladder. trend was seen in the samples from the Netherlands, where $41.6 \%$ of the samples were positive for both DMV-D10 and DMV-Holland, while none of the samples were positive for only DMV-D10 and DMV-Portland primers. These results indicate that the most prevalent DMV sequences in dahlia in both the United States and the Netherlands were those amplified by DMV-D10 primers.

Primers based on the conserved region among DMV-D10, DMV-Portland, and DMV-Holland (Fig. 1) were capable of amplifying all three viral sequences associated with dahlia mosaic (Fig. 2).

Pairwise comparisons of amino acid sequences representing each open reading frame of DMV-D10 (5) and DMV-Portland (GenBank accessions AY309480, AY309479, AY291588, AY291587, AY291586, AY291585) showed that the sequence identity between DMV-D10 and DMVPortland ranged from 47 to $73 \%$. This divergence suggests that there are at least two distinct caulimoviruses associated with dahlia mosaic. The third primer pair representing DMV-Holland amplifies a part of the coat protein gene and the reverse transcriptase gene (4). The ca. $1.2-\mathrm{kb}$ sequence (5) of DMV-Holland has 59.1\% sequence identity with the corresponding sequence in DMV-D10 and $41.2 \%$ identity with that of DMV-Portland. Thus, it appears that there are at least two and quite possibly three distinct caulimoviruses associated with dahlia. However, complete genome characterization of DMV-Holland is needed to establish whether DMVHolland is a distinct caulimovirus infecting dahlia. Our results also indicate that the coexistence of divergent caulimoviruses in a given dahlia plant is common. However, at present, there is no successful infectivity assay to correlate symptoms to a particular virus/sequence variant in dahlias.

Overall, the data indicate that there is a higher incidence of DMV-D10 in the United States, whereas in the Netherlands both DMV-D10 and DMV-Holland appear to be prevalent. These results also highlight the importance of testing dahlia planting material for viruses associated with dahlia mosaic in the light of our findings that DMV-D10, DMV-Holland, and DMVPortland sequences seem to be present at a different frequency in the United States than in the Netherlands. The wide prevalence of DMV-D10 (8 and this study) irrespective of the presence or absence of symptoms, combined with a high frequency of seed transmission (6), suggest potential integration of the D10 genome into the dahlia genome. Studies are in progress to verify this possibility.

DMV infection often remains latent, and as a result many infected but asymptomatic plants and propagating material are distributed, which might have contributed to the virus's widespread distribution in the United States (8). At present, PCR-based 
detection assay is the most reliable method of detecting DMV in dahlias. Considering the diversity in caulimoviruses associated with dahlia mosaic disease and the prevalence of mixed infections, use of primers specific to a single virus is not adequate for disease diagnosis, because it may lead to false negatives for other caulimoviruses that may be present.

\section{ACKNOWLEDGMENTS}

Research was supported in part by the Samuel and Patricia Smith Endowment for Dahlia Virus Research, created by the American Dahlia Society, and by funding from the USDA Northwest Nursery Crop Research Center. HRP wishes to acknowledge the support of OECD's Co-operative Research Programme: Biological Resource Management for Sustainable Agriculture Systems. PPNS No. 0446, Department of Plant Pathology, College of Agricultural, Human and Natural Resource Sciences, Agricultural Research Center, Project \# WNPO 0545, Washington State University, Pullman, WA 99164-6430, USA.
LITERATURE CITED

1. Albouy, J. 1995. Dahlia. 265-273 in: Virus and virus-like diseases of bulb and flower crops. G. Lobenstein, R. H. Lawson, and A. A. Brunt, eds. John Wiley \& Sons, Chichester, NY.

2. Bogunov, Y. V. 2006. Identification of Dahlia mosaic virus with molecular biological methods. Mol. Biol. 40:184-185.

3. Brunt, A. A. 1971. Some hosts and properties of dahlia mosaic virus. Ann. Appl. Biol. 67:357-368.

4. Nicolaisen, M. 2003. Partial molecular characterization of Dahlia mosaic virus and its detection by PCR. Plant Dis. 87:945-948.

5. Pahalawatta, V., Druffel, K., and Pappu, H. R. 2005. Molecular characterization of Dahlia mosaic virus genome. (Abstr.) Phytopathology 95:S79.

6. Pahalawatta, V., Druffel, K., and Pappu, H. R. 2007. Seed transmission of Dahlia mosaic virus in Dahlia pinnata. Plant Dis. 91:88-91.

7. Pappu, H. R., and Wyatt, S. D. 2003. Dahlia mosaic virus. A description of symptoms on dahlia. APSnet Image of the Week. Online/2003/IW000032. asp.
8. Pappu, H. R., Wyatt, S. D., and Druffel, K. L. 2005. Dahlia mosaic virus: Molecular detection and distribution in dahlia in the US. HortScience 40:697-699.

9. Presting, G. G., Smith, O. P., and Brown, C. R. 1995. Resistance to potato leaf roll virus in potato plants transformed with the coat protein gene or with vector control constructs. Phytopathology 85:436-442.

10. Rhoads, D. D., and Roufa, D. J. 1985. Emetine resistance of Chinese hamster cells: Structures of wild type and mutant ribosomal protein $\mathrm{S} 14$ mRNAs. Mol. Cell. Biol. 5:1655-1659.

11. Richins, R. D., and Shepherd, R. J. 1983. Physical maps of the genomes of Dahlia mosaic virus and Mirabilis mosaic virus - two members of the Caulimovirus group. Virology 124:208-214.

12. Thompson, J. D., Higgins, D. G., and Gibson, T. J. 1994. CLUSTAL W: Improving the sensitivity of progressive multiple sequence alignment through sequence weighting, positions-specific gap penalties and weight matrix choice. Nucleic Acids Res. 22:46734680 . 